\title{
Analysis on the Effective Development of Sports Network Educational
}

\author{
Resources \\ Li Qin ${ }^{1}$, Zimin Chang ${ }^{1}$ \\ ${ }^{1}$ Nanchang Institute of Science and Technology, Department of Physical Education, Jiangxi, \\ Nanchang, 330108 \\ 346591653@163.com
}

KEYWORDS: Education Resources; University Sports; Suggestions

\begin{abstract}
Over the years, the network of information technology development, beginning to infiltrate the various industries, the education sector as well. With the cause of national education reform deepening, various subjects have begun implementation of information technology development, especially among physical education. That way because in the past the traditional sports teaching, it is difficult to adapt to today's information society development situation, keep pace with the development, teaching sports network launched and implemented, and get good results. But where there are still some problems, that is, the development of effective education Sports Network resources issue, which directly affect the effect of the use of College Sports Network Education Resources. This paper analyzed for effective development of university sports online education resources, and with the launch of recommendations for reference.
\end{abstract}

\section{Introduction}

Social development, progress of the times, the education sector is constantly innovation and reform, the new method in which physical education, new technologies are continuing to emerge. In this situation, it is required not only in the sports teacher sports highlight, but also should be trained to master more new network of information technology. Today, the application of information technology networks are deep into the every day work of teachers and students and learning, developers typically work within the school network is extremely important educational resources, the school itself is directly related to the level of teaching quality, as a network resource teacher teaching, can fully play the main role of students, encourage students from passive to active, greatly cultivate students' innovative learning ability, so the development and construction of sports teaching resources is significant.

\section{1. Necessity of College Sports Network Education Resource Development}

\section{A. It Can Be Updated to Enhance the Efficiency of Teaching Sports Knowledge}

Sport in the world is very popular, so its development is very rapid, appropriate sports rules is constantly improving and updating them. This can be directly by means of online teaching resources to the transmission of such new sports knowledge and information to students, the general teaching of such content is very rich, it can really encourage students to quickly obtain the latest information in the field among sports. Physical education and the use of network resources to help 
students learn the most regulated form of action demonstration by the network, and may complicate actions directly down into slow continuous action to help students quickly master the relevant sports knowledge.

\section{B. It can Improve Network Physical Teaching Resource Utilization and Investment Returns}

Most colleges and universities in itself a serious lack of physical education teaching methods and theory, systematic training, particularly the corresponding theoretical guidance in network sports a serious lack of resources, instructional design, which led directly to the construction of sports among the teaching resources, too much emphasis on design work, thereby ignoring the serious design work on sports project teaching process. Eventually leading Sports Teaching Network Resources under the targeted and pedagogy have serious weak. Major colleges and universities in order to promote the development of a network of physical education, have invested significant resources in building a network among the PE teaching resources, but did not get to with the corresponding benefit, even if a lot of resources have been developed also did not get re-use, a direct result of severe low utilization of its teaching resources, is difficult to truly meet the needs of contemporary Physical Education.

\section{It can Provide A Good Platform for the Exchange of Experience and Teaching Ideas}

In addition to a number of national, provincial network curriculum, teaching resources within the network sports most colleges and universities are in strict accordance with the respective inner College PE teachers' curriculum construction and teaching needs of design, there are many self-developed teaching materials and courseware materials etc., it is usually easy to be directly affected by copyright and related concepts, even if most teachers is to develop the appropriate network resources are also used to own teaching them, are generally reluctant to provide free for others to use. This personalized sports teaching situation, led directly to the same kind of professional teachers completely unwilling to others using direct resources to start teaching, so the major colleges and universities in order to build a network of teaching resource, it is necessary to eliminate network Physical Education Resources Development a series of such problems, so as to realize the complementary advantages between individual teachers. Thus even in between school and inter-school will also enjoy better between the various sports disciplines teaching resources, and ultimately to promote good learning and mutual exchange of teachers, teaching sports to promote more in-depth development.

\section{2. Problems of College Sports Network Education Resources Development Faced}

\section{A. Information Waste of Resources and Application Efficiency is Not High}

Since the sports sector within the current major universities generally in a relatively independent status, its shared sense of serious deficiencies, leading to major colleges and universities in the educational process of information technology, the development and construction of its own sports network resources in a separate status. Physical education and most network resources because of their different development units, and its practical application system often into the system, close contact with each other less and less, a direct result of the case of the generation of information islands. Physical education in today's information-increasingly large, the corresponding information island has become increasingly evident in the past is not high integration of sports information construction completely unable to meet the needs of today's physical education, resulting in the generation of conflict. 


\section{Lack of Uniform Development Standards}

College Sports Network in the development of educational resources in the process, because the development and construction of ways and means there are many in the country also does not specifically developed technical standards for classification and a corresponding network of educational resources. And nor Physical Education Resources types and data formats, etc. unified description of its storage resources, there are significant differences, a direct result of Physical Education network resources become more and more messy, even direct duplication of development and construction case. Physical education is now growing data, the corresponding standard and consistency is increasingly clear that the interface is not compatible with each other, which are a serious impediment to the development and construction of College Sports Network Education Resources.

\section{E. Redundant Construction Serious, Quality Level is Not High}

Today curriculum Physical Education Resources adopted by the whole set up is more complete, mainly related to a number of sports content, and a lot of information on the development of sports also are covered. But because of financial problems and their mutual interest, leading to various colleges and universities have adopted an independent buyer or development approach, which developed independently of resources among a large part are some low-level, iterative development sports network construction educational resources ones. Even in some network resources which does not reflect the prospects for the development of sports, in the content nor enrich and timely updated, so completely unable to meet the students' learning and training needs. In this context, the availability and practicality of most college sports network resources are very limited, a direct result of the use of network resources and utilization of sports is very low.

\section{Recommendation 3. College Sports Network Resource Development}

Development of university sports network resources, is an important indicator of a school's progressive ideas, the most important is its direct non-professional sports colleges provide a good opportunity to perform. With the network development of Physical Education Resources, various departments within the College and educators to exchange it will become more convenient, to protect teachers and students can quickly browse and access the Internet, the network once it is missing its network educational resources will be impossible, essentially that is a waste of resources.

Physical Education Resources professional with distinctive characteristics, which need to grasp this feature to enhance the quality of internal network resources as much as possible, but because of various colleges and universities within the professional, original and too few resources, so we need to change strategy invite relevant experts and relevant theoretical purpose sports workers and teachers collaborate to achieve development. In the application you need to pay attention to practical results, the implementation of reform and innovation in the traditional model based on physical education, prompting more suitable for the needs of the future development of colleges and universities.

Development of Physical Education Resources must proceed from reality, which most schools are focusing on the development of the appropriate hardware, but in software development which directly represents the teachers of the true level. If the internal hardware resources to the development of universities well, and teachers do not understand or not to use this teaching is a failure of education. It requires teachers Sports Network Resources development at the same time, along with their simultaneous development, to integrate with the social aspect, conscientiously 
study and teaching of modern sports architecture, the introduction of the advanced nature of sports knowledge theory, the real effective development of sports network resources, and fully utilized.

\section{Conclusion}

In summary, the College Sports Network Education Resources is the product of a network of information technology development, which effectively improved the Physical Education mode, which enables the development of more comprehensive school PE teachers, students self-learning ability will be improved, and thus improve the physical education teaching quality and efficiency. Thus, the effective development of significance on college major online education resources, the development of college physical education played a major role.

\section{REFERENCE:}

[1] Shi Haixia. Sports Network Education Research Universities in China [J]. Sports Science, 2014,01: 153-155.

[2] Zhao Shi, Yang Dongming, etc. Survey of College Sports Network Education Resource Sharing [J]. Modern Sports Science, 2014,17: 89-90.

[3] Yang Ming. Thoughts on Balanced Development of College Sports Network Education Resources [J]. theory and modern, 2011,01: 113-116. 